\title{
Stage IIB Anal Cancer AJCC v8
}

National Cancer Institute

\section{Source}

National Cancer Institute. Stage IIB Anal Cancer A/CC v8. NCI Thesaurus. Code C133799.

Stage IIB includes: T3, NO, MO. T3: Tumor larger than $5 \mathrm{~cm}$. N0: No regional lymph node metastasis. M0: No distant metastasis. (AJCC 8th ed.) 